\title{
Professional Pharmacy Services and Patient Complexity: An Observational Study
}

Teegan A. Ignacy ${ }^{1}$, Ximena Camacho ${ }^{2}$, Muhammad M. Mamdani ${ }^{1,2,3,4,6}$, David N. Juurlink ${ }^{2,3,5,7,8}$, J. Michael Paterson ${ }^{2,3,9}$, Tara Gomes $1,2,3,6$

1. Leslie Dan Faculty of Pharmacy, University of Toronto, Ontario, Canada; ${ }^{2 .}$ Institute for Clinical Evaluative Sciences, Toronto, Ontario, Canada; ${ }^{3}$ Institute of Health Policy, Management, and Evaluation, University of Toronto, Ontario, Canada; ${ }^{4}$ Department of Medicine, St. Michael's Hospital, Toronto, Ontario, Canada; ${ }^{5 .}$ Department of Medicine, University of Toronto, Toronto, Ontario, Canada; ${ }^{6}$ Li Ka Shing Knowledge Institute, St. Michael's Hospital, Toronto, Ontario, Canada; ${ }^{7}$. Department of Pediatrics, University of Toronto, Toronto, Ontario, Canada; ${ }^{8}$. The Sunnybrook Research Institute, Sunnybrook Health Sciences Centre, Toronto, Ontario, Canada; 9. Department of Family Medicine, McMaster University, Hamilton, Ontario, Canada.

Received, September 8, 2015; Revised, September 17, 2015; Accepted, December 3, 2015; Published, December 3, 2015.

ABSTRACT - PURPOSE: To examine the association between the provision of professional pharmacy services (PPS) and patient complexity as determined by the number of distinct medications dispensed in Ontario. METHODS: We conducted a cross-sectional study among all individuals dispensed one or more medications under the Ontario Public Drug Program (OPDP) between April 1 $1^{\text {st }}, 2012$ and March $31^{\text {st }}, 2013$. We compared characteristics of patients receiving 1 or more PPS to those receiving no PPS. To assess the relationship between patient complexity (as measured by the number of chronic medications dispensed) and receipt of PPS, we reported the number and proportion of patients eligible for Ontario Drug Benefits (ODB) who received a PPS within each patient complexity group, and compared these proportions using the CochranArmitage test. RESULTS: Over the 1-year study period, 27.1\% ( $\mathrm{N}=799,674$ of 2,946,183) of ODB beneficiaries received at least one professional pharmacy service. Among these services, more than two-thirds of the patients received a MedsCheck service ( $\mathrm{N}=511,490 ; 64.0 \%)$. Overall, individuals who received a PPS tended to be older, more likely to reside in a long-term care (LTC) facility, have multiple comorbidities, and were more likely to have been prescribed 9 or more medications in the past year. As patient complexity increased, the proportion of ODB beneficiaries who received PPS also increased; $3.0 \%$ of individuals prescribed between 1 and 2 medications in the past year received PPS, while $53.6 \%$ of those treated with 13 or more medications received PPS $(p<0.0001)$. CONCLUSIONS: Although the findings of our study suggest the use of PPS increases with patient complexity, many complex patients are not receiving these services. Further studies are required to better understand why patients do not access these services, the impact of professional pharmacy services on patient health outcomes, and their value for the health care system.

This article is open to POST-PUBLICATION REVIEW. Registered readers (see "For Readers") may comment by clicking on ABSTRACT on the issue's contents page.

\section{INTRODUCTION}

Increasing scrutiny of health care budgets has pushed healthcare systems in several jurisdictions to expand the provision of services by allied health care professions. The expansion of professional pharmacy services (PPS) aims to better utilize the specialized knowledge of pharmacists to provide pharmaceutical patient care while increasing the efficiency of the healthcare system and improving patient outcomes. In particular, PPS aim to improve pharmaceutical care and address gaps in our system whereby medication errors occur. Many PPS focus on patients taking multiple medications, since polypharmacy predisposes patients to adverse drug reactions (1-3), drug-drug interactions $(4,5)$ and non-adherence $(6,7)$.

The Ontario Public Drug Program initiated the MedsCheck Program in 2007 to address concerns around medication safety and polypharmacy. Ontarians taking 3 or more medications for a chronic condition are eligible for an annual one-on-

Corresponding author: Tara Gomes, St. Michael's Hospital, 30 Bond Street, Toronto, Ontario, Canada; Email: GomesT@smh.ca 
one meeting with their pharmacist to review their medications, better understand their medication therapy, and ensure that medications are being taken as prescribed (8). Since 2007, MedsCheck has been expanded with particular foci on patients with diabetes (MedsCheck Diabetes), residents of longterm care homes (MedsCheck Long-Term Care [LTC]) and recipients of home care (MedsCheck at Home). Other services that have since been made available include the Pharmaceutical Opinion Program, whereby pharmacists who identify problems related to drug therapy work alongside their patients' physicians and make recommendations to improve their therapy. Finally, the Pharmacy Smoking Cessation Program is a comprehensive program in which pharmacists counsel and monitor patients who wish to quit smoking. The above services are compensated to varying degrees by the Ontario Public Drug Program. Similar programs exist in other jurisdictions (9-11) and thus Ontario's experience is a case study in the implementation of these services.

Despite the introduction of targeted PPS over the past several years, little is known about the extent to which these services are used across Ontario, and whether they are being delivered to patients most at risk of adverse drug events. The objective of this study was to assess the extent to which patient complexity was related to provision of PPS in Ontario.

\section{METHODS}

We conducted a population-based cross-sectional study among all active ODB beneficiaries (defined as those who received one or more prescription drugs reimbursed by the Ontario Public Drug Program) between April 1 ${ }^{\text {st }}, 2012$ and March 31 ${ }^{\text {st }}$, 2013. Within this cohort, we stratified patients according to their receipt of a PPS over the study period and type of PPS received. PPS offered in Ontario included MedsCheck, MedsCheck at Home, MedsCheck LTC, MedsCheck Diabetes, Pharmaceutical Opinion Program, and the Pharmacy Smoking Cessation Program. This study was approved by the Research Ethics Board of Sunnybrook Health Sciences Centre, Toronto, Ontario.

\section{Data Sources}

We used the Ontario Drug Benefit (ODB) database to identify all patients eligible for public drug coverage, and all PPS provided over the study period. This database contains computerized records for all prescriptions and PPS reimbursed through the public drug program in Ontario, and has an error rate of less than $1 \%$ (12). We identified patient demographics, including age, gender, income quintile and location of residence, using the Registered Persons Database, which contains information on all Ontarians who ever received a health card number. Finally, we used the Canadian Institute for Health Information (CIHI) Discharge Abstract Database, the CIHI National Ambulatory Care Reporting System, and the Ontario Health Insurance Program Database to identify patient history of inpatient hospitalizations, emergency department visits, and outpatient physician visits in the past 2 years, respectively.

\section{Characteristics of Patients Receiving Professional Pharmacy Services}

We identified all individuals who received at least one PPS over the study period and compared the characteristics of these patients to those eligible for public drug coverage who received no PPS over the same period. The index date for the cohort of patients receiving PPS was the date of the first service received over the study period. Among those receiving no PPS, the index date was defined as the date of their first medication received over the study period. Variables measured included age, sex, neighbourhood income quintile, location of residence (LTC or community), and rural or urban residence. Patient comorbidity was defined using the Johns Hopkins Aggregated Diagnostic Groups (ADGs) based on hospital visits, emergency department visits and physician claims in the 2 years prior to the index date. ADGs were used because these generate clinically similar clusters of patients based on recent diagnoses (13). Furthermore, patient complexity was defined based on the number of distinct drugs dispensed to the patient in the past 1 year, categorized into 1-2, 3-4, $5-6,7-8,9-12$ and 13 or more drugs (14). We applied the number of distinct drugs used over a one-year period as a surrogate for patient complexity, which has shown to predict future physician visits, healthcare expenditures, mortality, and hospitalizations (14). 


\section{Professional Pharmacy Services and Patient Complexity}

To assess the relationship between increasing patient complexity and receipt of PPS, we reported the number and proportion of ODB eligible patients who received a PPS within each patient complexity group. In the analysis stratified by PPS type, patients who received multiple types of PPS over the year were included once in each PPS category.

\section{STATISTICAL ANALYSIS}

All binary variables were summarized using proportions, and continuous variables were summarized using medians and interquartile ranges (IQRs). We compared characteristics of patients who received PPS and those who did not using standardized differences. A standardized difference greater than 0.10 was defined as a meaningful difference (15). We used the Cochran-Armitage trend test to determine whether there was a statistically significant increase in the prevalence of PPS by patient complexity. All analyses were conducted using SAS Version 9.3 (SAS Institute, Cary, North Carolina) at the Institute for Clinical Evaluative Sciences.

\section{RESULTS}

In fiscal year 2012, 27.1\% $(\mathrm{N}=799,674$ of $2,946,183$ ) of Ontarians eligible for public drug coverage received at least one PPS (Table 1). Among these services, two-thirds of the patients received a MedsCheck service $(\mathrm{N}=511,490), 15.4 \%$ $(\mathrm{N}=123,216)$ received a MedsCheck Diabetes service, $11.3 \%(\mathrm{~N}=90,288)$ received MedsCheck in LTC, 3.3\% $(\mathrm{N}=26,529)$ received MedsCheck at home, and $22.3 \%(\mathrm{~N}=178,342)$ were part of the Pharmaceutical Opinion Program (Table 2). Only $0.5 \% \quad(\mathrm{~N}=4,137)$ of patients were part of the Pharmacy Smoking Cessation Program.

Overall, individuals receiving PPS in Ontario were considerably different from those who received no services (Table 1). In particular, they tended to be older (median 73 years vs. 66 years) and more likely to reside in a LTC facility $(10.9 \%$ vs. $0.3 \%$ ). Furthermore, those receiving PPS were more likely to have multiple comorbidities $(34.5 \%$ with 10 or more ADGs) compared to those who received no such services $(19.8 \%$ with 10 or more ADGs), and were more likely to have been prescribed 13 or more medications in the past year
(28.5\% vs. 9.3\% among PPS recipients and nonrecipients, respectively).

In general, we found that as patient complexity increased, the proportion of ODB beneficiaries who received PPS also increased $(\mathrm{p}<0.0001)$ (Figure 1). For example, few individuals (3.0\%) prescribed 1 to 2 medications in the past year received a PPS, while greater than half $(53.6 \%)$ of those who received 13 or more medications received a PPS. Furthermore, the types of services provided became more variable as patient complexity increased (Figure 2). Among lower complexity patients, MedsCheck was the most commonly provided service; however as complexity increased, other services including Pharmaceutical Opinion Program, MedsCheck LTC and MedsCheck Diabetes became more prevalent.

\section{DISCUSSION}

This population-based study of PPS use in Ontario found that approximately one-third $(27.1 \%)$ of patients eligible for public drug coverage received at least one service over the course of a year, and that the use of these services appears to increase as patient complexity increases. However, despite this trend, almost half of the most complex patients (those prescribed 13 or more prescriptions) did not receive any such services, suggesting that there is significant room for improvement of access and expansion to patients who could benefit from these services.

These low rates of PPS use are surprising given that $98 \%$ of pharmacies in Ontario provide MedsCheck services (8). Low observed rates may be driven by pharmacies infrequently offering these services. Many pharmacies may have limited staff and time to provide these services, or may be apprehensive to engage in new services that may interfere with workflow (16). Furthermore, because pharmacy reimbursement for services is not tied to patient complexity, some pharmacists may be deterred from providing these services to highly complex patients taking multiple medications given the time commitment required to conduct the service (17). The introduction of new PPS in Alberta and Saskatchewan revealed varying levels of acceptability from pharmacists based on factors including the perception of the ability of services to improve patient care, easy incorporation into workflow, ability to provide adequate follow-up and liability $(18,19)$. 
Table 1. Baseline characteristics of Ontario Drug Benefit beneficiaries who have filled at least one prescription and have received any professional pharmacy services versus patients who have received no services between April 2012 and March 2013

\begin{tabular}{|c|c|c|c|}
\hline 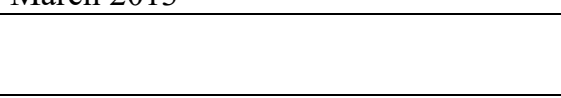 & $\begin{array}{c}\text { Any Professional } \\
\text { Pharmacy Service }\end{array}$ & No Services & $\begin{array}{c}\text { Standardized } \\
\text { Differences }\end{array}$ \\
\hline & $N=799,674$ & $N=2,146,509$ & \\
\hline $\begin{array}{l}\text { Age at cohort entry in years } \\
\text { (Median, IQR) }\end{array}$ & $73(66-81)$ & $66(45-74)$ & 0.62 \\
\hline \multicolumn{4}{|l|}{ Sex } \\
\hline Undefined & $2,004(0.3 \%)$ & $24,636(1.1 \%)$ & 0.09 \\
\hline Female & $448,178(56.0 \%)$ & $1,158,394(54.0 \%)$ & 0.04 \\
\hline Male & $349,492(43.7 \%)$ & $963,479(44.9 \%)$ & 0.02 \\
\hline \multicolumn{4}{|l|}{ Neighbourhood income quintile } \\
\hline Q1 (lowest) & $184,485(23.1 \%)$ & $528,601(24.6 \%)$ & 0.04 \\
\hline$Q 2$ & $166,590(20.8 \%)$ & $435,376(20.3 \%)$ & 0.01 \\
\hline$Q 3$ & $151,977(19.0 \%)$ & $388,160(18.1 \%)$ & 0.02 \\
\hline$Q 4$ & $149,788(18.7 \%)$ & $383,179(17.9 \%)$ & 0.02 \\
\hline Q5 (highest) & $141,166(17.7 \%)$ & $376,540(17.5 \%)$ & 0.00 \\
\hline Missing & $5,668(0.7 \%)$ & $34,653(1.6 \%)$ & 0.08 \\
\hline \multicolumn{4}{|l|}{ Location of residence } \\
\hline Residents of LTC facilities & $87,460(10.9 \%)$ & $6,525(0.3 \%)$ & 0.63 \\
\hline Community-dwelling seniors & $557,113(69.7 \%)$ & $1,241,182(57.8 \%)$ & 0.24 \\
\hline Community-dwelling non-seniors & $155,101(19.4 \%)$ & $898,802(41.9 \%)$ & 0.48 \\
\hline \multicolumn{4}{|l|}{ Rural residence } \\
\hline Missing & $3,129(0.4 \%)$ & $28,232(1.3 \%)$ & 0.09 \\
\hline No & $699,952(87.5 \%)$ & $1,834,569(85.5 \%)$ & 0.06 \\
\hline Yes & $96,593(12.1 \%)$ & $283,708(13.2 \%)$ & 0.03 \\
\hline \multicolumn{4}{|l|}{ Number of comorbidities ${ }^{1}$} \\
\hline 0 & $4,728(0.6 \%)$ & $53,003(2.5 \%)$ & 0.14 \\
\hline $1-5$ & $215,754(27.0 \%)$ & $875,883(40.8 \%)$ & 0.29 \\
\hline $6-9$ & $303,183(37.9 \%)$ & $791,687(36.9 \%)$ & 0.02 \\
\hline $10+$ & $276,009(34.5 \%)$ & $425,936(19.8 \%)$ & 0.35 \\
\hline \multicolumn{4}{|l|}{ Patient Complexity: Drugs ${ }^{2}$} \\
\hline $1-2$ & $24,041(3.1 \%)$ & $793,327(37.0 \%)$ & 0.80 \\
\hline $3-4$ & $84,622(10.6 \%)$ & $387,728(18.1 \%)$ & 0.21 \\
\hline $5-6$ & $125,979(15.8 \%)$ & $291,366(13.6 \%)$ & 0.06 \\
\hline $7-8$ & $130,302(16.3 \%)$ & $215,685(10.0 \%)$ & 0.19 \\
\hline $9-12$ & $205,913(25.7 \%)$ & $259,372(12.1 \%)$ & 0.38 \\
\hline 13 or more & $227,817(28.5 \%)$ & $199,031(9.3 \%)$ & 0.57 \\
\hline
\end{tabular}




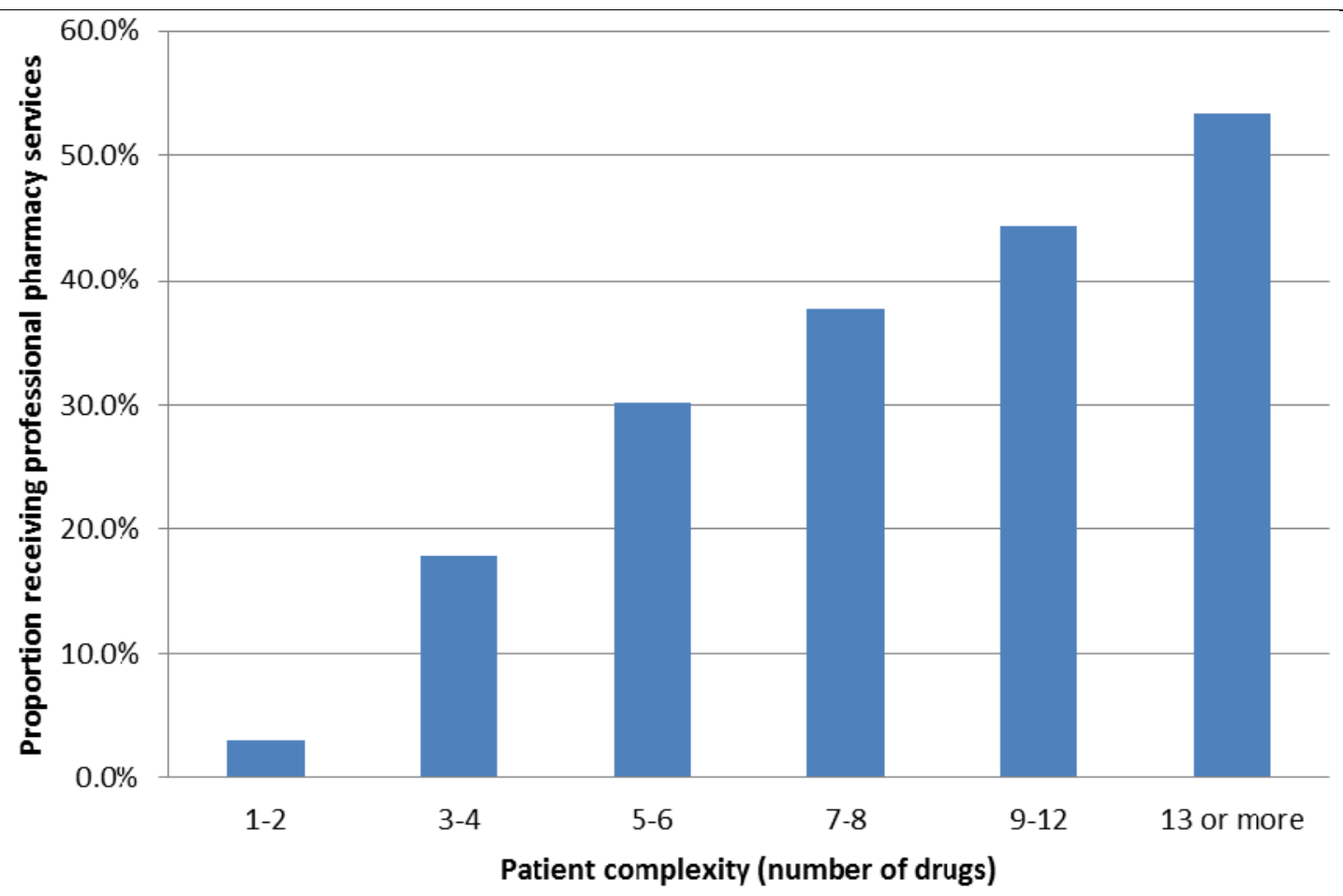

Figure 1. Proportion of Ontario Drug Benefit beneficiaries receiving any professional pharmacy service(s) by patient complexity group between April 2012 and March 2013.

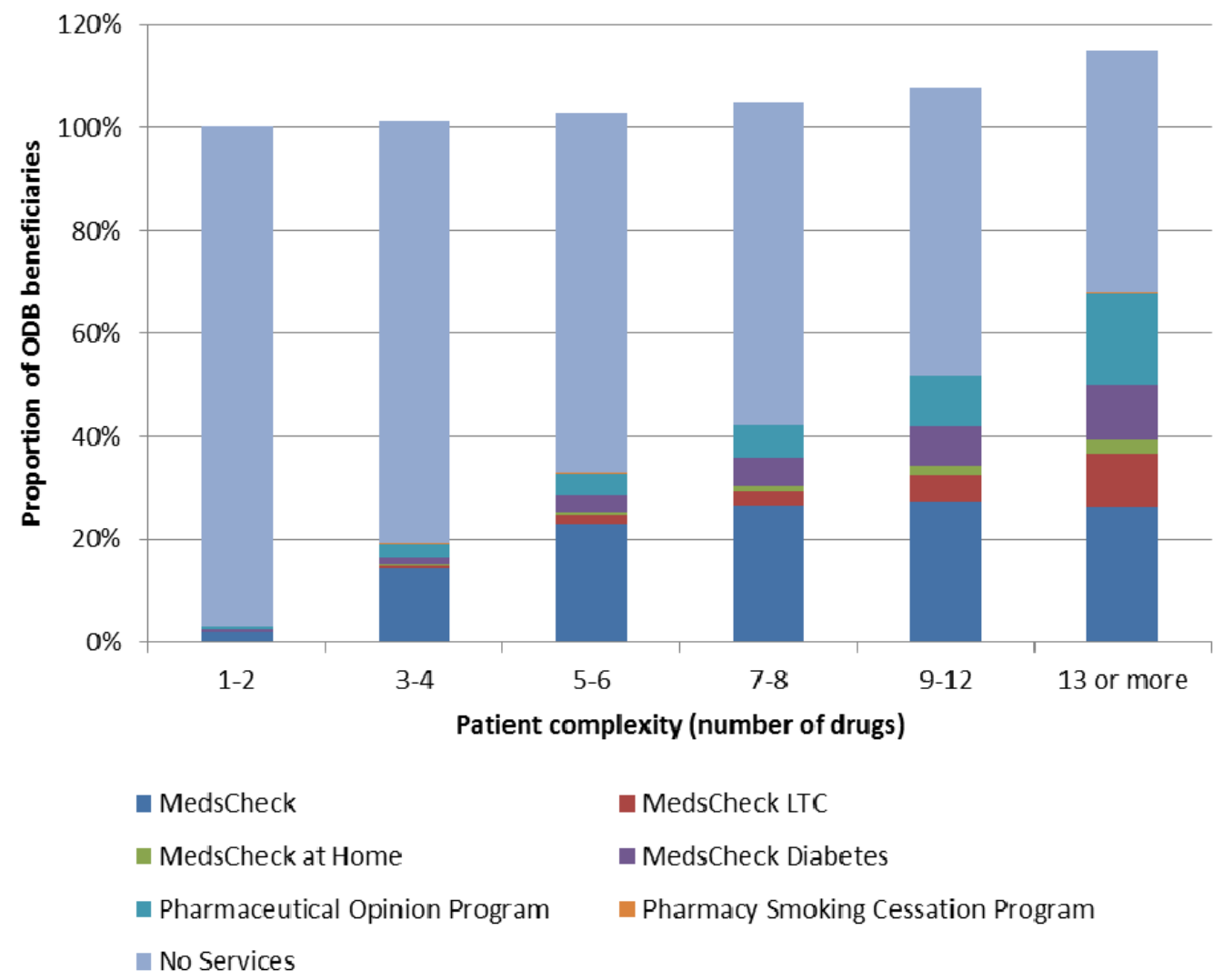

Figure 2. Prevalence of Ontario Drug Benefit beneficiaries receiving one or more professional pharmacy services by patient complexity, broken down by professional pharmacy service type between April 2012 and March 2013. Note that total pecentages add up to more than $100 \%$ because individuals can receive more than one type of service. 
Additionally, patient compliance and refusal of service may be partially driving these results. Studies in other jurisdictions have shown that following the implementation of similar services, patient refusal of these services steadily declined over time $(21,22)$. In addition to increased uptake, patient perceptions of PPS in other jurisdictions have considerably improved over time in the areas of medications reviews (22) and with pharmacists as immunizers (23). Each of the included services in our analysis have been available for varying lengths of time from the implementation of the MedsCheck Program in 2007 to the implementation of the Smoking Cessation and Pharmaceutical Opinion programs in 2011 (24-26). At the time of this study all programs were still relatively new and uptake of services is likely to rise with increased familiarity.

Complex patients are among the most vulnerable subjects, as well as being a group that consumes a great amount of healthcare resources. As a result, several programs exist that have been designed to target pharmacy services towards these high needs patients. For example, Fairview Pharmacy Service's Medication Therapy Management (MTM) Program in the United States uses internal databases to identify complex patients using criteria that include individuals not meeting their goals of therapy, those missing key drug therapies, and those with high utilization patterns and risk (27). Studies analyzing the effect of Fairview Pharmacy's MTM services targeting diabetes and asthma management have demonstrated statistically significant improvements in clinical parameters for both groups $(27,28)$. Furthermore, in a randomized controlled trial conducted in Ontario, Hogg et al. showed that in a study randomizing 'at-risk' patients to either standard care or to an interdisciplinary team, which included the use of PPS provided by a pharmacist, the team care approach led to improved quality of care for chronic disease management (29). Although other jurisdictions across Canada and internationally have implemented PPS, we are unable to compare the uptake of services in Ontario to that of other jurisdictions since there is a paucity of evidence related to this topic, particularly those which compare service uptake by patient complexity. This highlights the need for further research in this area, which will allow for comparisons between jurisdictions that can inform policy-makers as they continue to develop and review these services.
Our study has several strengths, including the population-based nature of the analysis, and the ability to look at associations between receipt of PPS in regular practice and patient complexity and comorbidity. However, some limitations merit emphasis. First, our definition of PPS is based on specific services for which pharmacists can bill for reimbursement. It is possible that some pharmacists are providing these services to patients without billing for reimbursement, which we would not capture. However, given that these services are readily reimbursed, it is unlikely to have a large influence on our findings. Second, we restricted our population to those individuals who are eligible for public drug coverage in Ontario to ensure that we could determine their past medication history. Since all individuals aged 65 and older in Ontario are eligible for drug coverage, we estimate that this cohort captures a large proportion of complex patients.

\section{CONCLUSION}

Although the prevalence of use of PPS in Ontario is fairly high, there remain a large number of underserviced patients with complex medical needs who may benefit from these programs. Future research is required to better understand the facilitators and barriers to access of PPS among complex patients and, ultimately, the impact of PPS on patient health outcomes.

\section{REFERENCES}

1. Goldberg PB, Roberts J. Pharmacologic basis for developing rational drug regimens for elderly patients. Med Clin North Am, 1983; 67:315-331.

2. Hoigné R, Lawson DH, Weber E. Risk factors for adverse drug reactions - epidemiological approaches. Eur J Clin Pharmacol, 1990; 39:321325.

3. Baena MI, Faus MJ, Fajardo PC, Luque FM, Sierra F, Martinez-Olmos J, Cabrera A, Fernandez-Llimos F, Martinez-Martinez F, Jiménez J, Zarzuelo A. Medicine-related problems resulting in emergency department visits. Eur J Clin Pharmacol, 2006; 62:387-393.

4. McInnes GT, Brodie MJ. Drug interactions that matter. A critical reappraisal. Drugs, 1988; 36:83110.

5. Doan J, Zakrzewski-Jakubiak H, Roy J, Turgeon J, Tannenbaum C. Prevalence and risk of potential cytochrome $\mathrm{P} 450$-mediated drug-drug interactionsin 
older hospitalized patients with polypharmacy. Ann Pharmacother, 2013; 47:324-332.

6. Hanlon JT, Schmader KE, Ruby CM, Weinberger M. Suboptimal prescribing in older inpatients and outpatients. J Am Geriatr Soc, 2001; 49:200-209.

7. Gellad WF, Grenard JL, Marcum ZA. A systematic review of barriers to medication adherence in the elderly: looking beyond cost and regimen complexity. Am J Geriatr Pharmacother, 2011; 9:11-23.

8. MOHLTC, 2009. Improving Ontario's Publicly Funded Drug System: Results for Ontarians - 2007 Annual Report of the Executive Officer, Ontario Drug Benefit Programs. $<$ http://www.health.gov.on.ca/en/common/ministry/ publications/reports/drugs_annual_report2007/drugs _annual_report2007.pdf $>$ Accessed June 3, 2014.

9. Alberta Blue Cross, 2014. Pharmacy Services Compensation Update $<$ http://www.rxa.ca/pharmacy-servicesframework/for-the-pharmacist.aspx $>$ Accessed July 19, 2015.

10. British Columbia Pharmacy Association (BCPhA), 2015. Medication review services. $<$ http://www.bcpharmacy.ca/medication-reviewservice $>$ Accessed July 19, 2015.

11. Pharmacists Association of Saskatchewan (PAS), 2015. Professional Services.

$<$ http://www.skpharmacists.ca/fundedservices/provincial/professional-services $>$ Accessed July 19, 2015.

12. Goel, V.; Williams, J.; Anderson, G.; BlacksteinHirsch, P.; Fooks, C.; Naylor, D., Patterns of Health Care in Ontario. 2nd ed. Canadian Medical Association, Ottawa, Ontario, Canada, 1996.

13. Weiner JP. The Johns Hopkins ACG System: Technical reference guide. Version 9.0, December 2009.

14. Schneeweiss S, Seeger JD, Maclure M, Wang PS, Avorn J, Glynn RJ. Performance of comorbidity scores to control for confounding in epidemiologic studies using claims data. Am J Epidemiol, 2001; 154:854-864.

15. Mamdani M, Sykora K, Li P, Normand SL, Streiner DL, Austin PC, Rochon PA, Anderson GM. Reader's guide to critical appraisal of cohort studies: 2 . Assessing potential for confounding. BMJ, 2005; 330:960-962.

16. Grindrod K, Sanghera N, Rahmaan I, Roy M, Tritt M. Living MedsCheck: Learning how to deliver MedsCheck in community practice in Ontario. Can Pharm J, 2013; 146:33-38.

17. Grindrod KA, Marra CA, Colley L, Tsuyuki RT, Lynd LD. Pharmacists' preferences for providing patient-centered services: a discrete choice experiment to guide health policy. Ann Pharmacother, 2010; 44:1554-1564.
18. Perepelkin J, Dobson RT. Perceptions of Saskatchewan community pharmacists regarding a prior-authorization program. J Manag Care Pharm, 2007; 13:589-597.

19. Hutchison M, Lindblad A, Guirguis L, Cooney D, Rodway M. Survey of Alberta hospital pharmacists' perspectives on additional prescribing authorization. Am J Health Syst Pharm, 2012; 69:1983-1992.

20. Rosenthal M, Tsao NW, Tsuyuki RT, Marra CA.Identifying relationships between the professional culture of pharmacy, pharmacists' personality traits, and the provision of advanced pharmacy services. Res Social Adm Pharm, 2015; May 8. pii: S1551-7411(15)00083-2. doi: 10.1016/j.sapharm.2015.05.003. [Epub ahead of print].

21. Barnett MJ, Frank J, Wehring H, Newland B, VonMuenster S, Kumbera P, Halterman T, Perry PJ. Analysis of pharmacist-provided medication therapy management (MTM) services in community pharmacies over 7 years. J Manag Care Pharm, 2009; 15:18-31.

22. Benrimoj SI, Roberts AS. Providing patient care in community pharmacies in Australia. Ann Pharmacother, 2005; 39:1911-1917.

23. Hogue MD, Grabenstein JD, Foster SL, Rothholz MC. Pharmacist involvement with immunizations: a decade of professional advancement. J Am Pharm Assoc (2003), 2006; 46:168-179.

24. MOHLTC, 2015.2 MedsCheck $<\underline{\text { http://health.gov.on.ca/en/public/programs/drugs/m }}$ edscheck/medscheck original.aspx $>$ Accessed July 19, 2015.

25. MOHLTC, 2015. Pharmacy Smoking Cessation Program.

$<\underline{\text { http://www.health.gov.on.ca/en/pro/programs/drug }}$ s/smoking/> Accessed July 19, 2015.

26. MOHLTC, 2015. Pharmaceutical Opinion Program. $<$ http://www.health.gov.on.ca/en/pro/programs/drug s/smoking/> Accessed July 19, 2015.

27. Brummel A, Lustig A, Westrich K, Evans MA, Plank GS, Penso J, Dubois RW. Best Practices: Improving patient outcomes and costs in an ACO through comprehensive medication therapy management. J Manag Care and Spec Pharm, 2014; 20:1152-1158.

28. Brummel AR, Soliman AM, Carlson AM, de Oliveira DR. Optimal diabetes care outcomes following face-to-face medication therapy management services. Popul Health Manag, 2013;16:28-34.

29. Hogg $\mathrm{W}$, Lemelin J, Dahrouge S, Liddy $\mathrm{C}$, Armstrong CD, Legault F, Dalziel B, Zhang W. Randomized controlled trial of anticipatory and preventative multidisciplinary team care. Can Fam Physician, 2009; 55:e76-e85. 
Table 2: Proportion of all ODB beneficiaries who have received a professional pharmacy service, stratified by patient complexity, April 2012 - March 2013

\begin{tabular}{|c|c|c|c|c|c|c|c|c|}
\hline $\begin{array}{c}\text { Patient } \\
\text { Complexity: } \\
\text { Drugs }{ }^{1}\end{array}$ & $\begin{array}{c}\text { Any Professional } \\
\text { Pharmacy } \\
\text { Service }\end{array}$ & MedsCheck & MedsCheck LTC & $\begin{array}{c}\text { MedsCheck } \\
\text { at Home }\end{array}$ & $\begin{array}{c}\text { MedsCheck } \\
\text { Diabetes }\end{array}$ & $\begin{array}{c}\text { Pharma-ceutical } \\
\text { Opinion } \\
\text { Program }\end{array}$ & $\begin{array}{l}\text { Pharmacy } \\
\text { Smoking } \\
\text { Cessation } \\
\text { Program }\end{array}$ & No Services \\
\hline & $\mathrm{N}=799,674$ & $\mathrm{~N}=\mathbf{5 1 1 , 4 9 0}$ & $\mathrm{N}=\mathbf{9 0 , 2 8 8}$ & $\mathrm{N}=\mathbf{2 6 , 5 2 9}$ & $\mathrm{N}=123,216$ & $\mathrm{~N}=178,342$ & $\mathrm{~N}=4,137$ & $\mathrm{~N}=2,146,509$ \\
\hline $1-2$ & $\begin{array}{l}25,041 \\
(3.1 \%)\end{array}$ & $\begin{array}{l}16,682 \\
(3.3 \%)\end{array}$ & $\begin{array}{c}1,203 \\
(1.3 \%)\end{array}$ & $\begin{array}{c}373 \\
(1.4 \%)\end{array}$ & $\begin{array}{c}3,016 \\
(2.4 \%)\end{array}$ & $\begin{array}{c}4,871 \\
(2.7 \%)\end{array}$ & $\begin{array}{c}283 \\
(6.8 \%)\end{array}$ & $\begin{array}{l}793,327 \\
(37.0 \%)\end{array}$ \\
\hline $3-4$ & $\begin{array}{c}84,622 \\
(10.6 \%)\end{array}$ & $\begin{array}{c}67,164 \\
(13.1 \%)\end{array}$ & $\begin{array}{c}3,624 \\
(4.0 \%)\end{array}$ & $\begin{array}{c}1,427 \\
(5.4 \%)\end{array}$ & $\begin{array}{c}6,447 \\
(5.2 \%)\end{array}$ & $\begin{array}{l}11,324 \\
(6.3 \%)\end{array}$ & $\begin{array}{c}498 \\
(12.0 \%)\end{array}$ & $\begin{array}{l}387,728 \\
(18.1 \%)\end{array}$ \\
\hline $5-6$ & $\begin{array}{l}125,979 \\
(15.8 \%)\end{array}$ & $\begin{array}{c}96,092 \\
(18.8 \%)\end{array}$ & $\begin{array}{c}6,977 \\
(7.7 \%)\end{array}$ & $\begin{array}{c}2,553 \\
(9.6 \%)\end{array}$ & $\begin{array}{c}13,676 \\
(11.1 \%)\end{array}$ & $\begin{array}{c}17,866 \\
(10.0 \%)\end{array}$ & $\begin{array}{c}567 \\
(13.7 \%)\end{array}$ & $\begin{array}{l}291,366 \\
(13.6 \%)\end{array}$ \\
\hline $7-8$ & $\begin{array}{l}130,302 \\
(16.3 \%)\end{array}$ & $\begin{array}{c}91,687 \\
(17.9 \%)\end{array}$ & $\begin{array}{c}10,096 \\
(11.2 \%)\end{array}$ & $\begin{array}{c}3,458 \\
(13.0 \%)\end{array}$ & $\begin{array}{c}18,705 \\
(15.2 \%)\end{array}$ & $\begin{array}{c}22,329 \\
(12.5 \%)\end{array}$ & $\begin{array}{c}564 \\
(13.6 \%)\end{array}$ & $\begin{array}{l}215,685 \\
(10.0 \%)\end{array}$ \\
\hline $9-12$ & $\begin{array}{l}205,913 \\
(25.7 \%)\end{array}$ & $\begin{array}{l}127,910 \\
(25.0 \%)\end{array}$ & $\begin{array}{c}23,639 \\
(26.2 \%)\end{array}$ & $\begin{array}{c}7,092 \\
(26.7 \%)\end{array}$ & $\begin{array}{c}36,487 \\
(29.6 \%)\end{array}$ & $\begin{array}{c}45,764 \\
(25.7 \%)\end{array}$ & $\begin{array}{c}901 \\
(21.8 \%)\end{array}$ & $\begin{array}{l}259,372 \\
(12.1 \%)\end{array}$ \\
\hline 13 or more & $\begin{array}{l}227,817 \\
(28.5 \%)\end{array}$ & $\begin{array}{l}111,955 \\
(21.9 \%)\end{array}$ & $\begin{array}{c}44,749 \\
(49.6 \%)\end{array}$ & $\begin{array}{c}11,626 \\
(43.8 \%)\end{array}$ & $\begin{array}{c}44,885 \\
(36.4 \%)\end{array}$ & $\begin{array}{c}76,188 \\
(42.7 \%)\end{array}$ & $\begin{array}{c}1,324 \\
(32.0 \%)\end{array}$ & $\begin{array}{c}199,031 \\
(9.3 \%)\end{array}$ \\
\hline
\end{tabular}

